\title{
The Preliminary Test
}

M. W. ForTh. Senior Lecturer and Consultant Psychiatrist. Royal Liverpool Hospital, Liverpool

Suggestions have been made that the Preliminary Test for the Membership of the College should be modified in the direction of a reduced theoretical and enhanced clinical content. I would applaud such a move. Bchind it is the idea of testing, early in a junior's career, his or her talents for the processes central to the practice of their chosen specialty. This sort of test has for too long been lacking throughout the profession of medicine. There is no reason why psychiatry should not now, with the advantage of modern technology, set the pace by combining an element of aptitude testing in the earlist hurdle on the road to specialist status.

These ideas derive some support from the recent trend towards asking Membership candidates to interview their patients briefly in the presence of the examiners. Nevertheless, our current examination format only allows for an inference being made as to the potential suitability of a candidate for the practice of psychiatry. A new format should allow us to reduce the element of inference.

\section{Preliminary Test tapes}

I suggest that this could be most readily achieved by making the clinical part of a Preliminary Test a videotaped interview with a patient. The tape could be timed to last up to 20 minutes with a further $\mathbf{1 0}$ minutes (maximum) allowed for the candidate to record his initial thoughts on the case he has just seen. In our University Diploma Course in Psychotherapy in Liverpool, each aspiring diplomate has been required to make such a tape and these tapes have proved most useful in the evaluation process.

Preliminary Test tapes could be made by cach candidate at the nearest centre capable of producing a good standard of recording and of producing an adequate number of suitable patients. Almost any type of case could be used in this sort of test. I would also suggest that a candidate should be accompanied to the taping centre by his own clinical tutor, both as a support and to see fair play.

\section{Advantages}

I see several advantages to a taped element in the Preliminary Test, among them: (1) The test would be of central clinical skills' and knowledge, in particular, the rapid formation of rapport with and evaluation of the psychiatric patient: (2) The examiners, perhaps two in number, sitting at the College or in peripheral centres and seeing perhaps six to eight tapes per day could evaluate this whole process: (3) The examiners would have a better chance than at present to allow for unduly difficult (or unduly helpful!) patients: (4) The tape could be made at any time within an arbitrary limit, say three months, of the date of the rest of test: (5) A much wider range of patients than at conventional clinical examinations could readily be used since only one or two candidates need be examined at a centre on a given day. In the unlikely event of no suitable patient being available the taping session would merely be re-booked at a later date; (6) For similar reasons a candidate's indisposition on the set date need be of no disadvantage- (I myself took the Membership clinical with a temperature of $102^{\circ} \mathrm{F}$, perhaps the resulting mild unreality feeling was a help!): (7) The central organization of such a system could be less complex than in the current Membership format: (8) Significant disagreement between a pair of examiners or evidence of tendency to excessive harshness or leniency by a given pair could be readily referred to one or more arbiters who could see exactly the same material; (9) The logistics of the test would allow for the use of a less 'worked-over' type of patient. Some patients in the current Membership examination have been seen by numerous staff of good calibre and will tend to give, from long practice, a good history whatever they are asked! (10) I suspect that the exercise suggested would be cheaper to run than current clinical examinations- the main costs being examiners fees and a modest charge to cover use of taping facilities and loan or purchase of blank tapes.

\section{Disadvantages}

Disadvantages are several but, in my view, less significant than advantages: (1) Video-tape nervousness: This could be counteracted by allowing 'trial runs'. These should perhaps be standard as part of courses leading to the Preliminary Test. In any event my own experience both as a candidate and examiner would not convince me that the inevitable anxiety in making a tape for others to view is any worse than that engendered by 'live' examiners. (2) Artificiality: Again my own experience suggests that it is almost always the case that patient and interviewer forget the presence of cameras and microphone at an early stage in the proceedings: (3) Lack of control of the examination: This could be modified by appointing the local clinical tutor, or other suitable person at the taping centre, as supervisor. The time involved would not be great. but a certain amount of trust would be required. Acceptable uniformity of practice could be obtained by the issue of detailed guidance to tutors and supervisors and by occasional centrally held briefings.

I believe that my suggestions could form the basis of a practical and relevant examination at an early stage in a trainec's career. Others will see disadvantage or even advantages which I have omitted for brevity or failed to see, but I hope that this outline might contribute to a worthwhile debate. 